\title{
Analysis of 89 patients who underwent tube thoracostomy performed by general surgeons
}

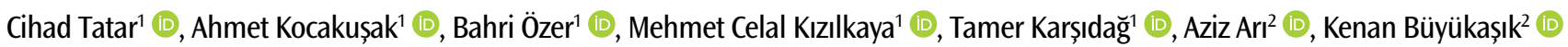

ABSTRACT Objective: Death due to thoracic trauma accounts for $20 \%$ of all trauma deaths. The aim of this study was to discuss the approach applied by general surgeons to thoracic trauma in our center.

Material and Methods: A total of 89 patients (82 male, 7 female; mean age: 26.8 years; range: 7 to 77 years) with thoracic trauma who were admitted to the emergency department and underwent thoracostomy performed by general surgeons between January 2008 and December 2013 were retrospectively analyzed.

Results: Penetrating trauma was found in 61 patients (68\%); this was the most common cause of thoracic trauma. Pneumothorax, the most common clinical sign, was found in 57 patients $(64 \%)$. Abdominal pathologies, the most common concomitant extra-thoracic pathologies, were found in 17 patients (19\%). Fifteen patients (17\%) underwent laparotomy due to intra-abdominal organ injuries. Splenic trauma and diaphragmatic injury were detected in five patients. Complications were seen in two patients (2.2\%): one had an air leak and one had persistent pneumothorax. Three patients with multi-trauma died in the early period due to additional pathologies. No mortality was seen in any patient due to thoracic trauma.

Conclusion: All general surgeons should be highly familiar with approaches to thoracic trauma, and necessary interventions should be performed in emergency situations. It is also essential to correctly identify patients who require timely and appropriate referral to a tertiary center to reduce the rates of mortality and morbidity.

ORCID IDs of the authors: C.T. 0000-0002-0407-9655, A.K. 0000-0001-9685-6660, B.A. $0000-0002-4326-2102$ M.C.K. 0000-0001-8314-9908 T.K. 0000-0002-6838-7454

A.A. $0000-0002-7806-2354$

K.B. 0000-0002-3449-1974

\section{Cite this paper as:}

Tatar C, Kocakuşak A, Özer B, Kızılkaya MC, Karşıdağ T, Arı

A, Büyükaşık K. Analysis of

89 patients who underwent

tube thoracostomy

performed by general surgeons. Turk J Surg 2018; 34: 49-52.

'Department of General Surgery, Haseki Training and Research Hospital, İstanbul, Turkey 2Department of General Surgery, İstanbul Training and Research Hospital, İstanbul, Turkey

This study was presented at the " $19^{\text {th }}$ Turkish National Congress of Surgery, 16-20 April 2014, Antalya, Turkey.

Address for Correspondence Cihad Tatar

e-mail: tatarcihad@gmail.com

Received: 15.08.2016

Accepted: 08.02.2017

Available Online Date: 03.09.2017

CCopyright 2018

by Turkish Surgical Association

Available online at

www.turkjsurg.com
Keywords: Hemothorax, pneumothorax, thoracic injury, tube thoracostomy

\section{INTRODUCTION}

Tube thoracostomy due to trauma may be regarded differently by general surgeons than by thoracic surgeons. Most cases in the literature are reported by thoracic surgeons. Mortality and morbidity rates are high in blunt or penetrating thoracic trauma. The mortality rate due to thoracic trauma is approximately 4\%-20\% (1). Therefore, early diagnosis and treatment are essential to provide respiratory continuity. Applying appropriate approaches to patients with thoracic trauma may substantially reduce mortality and morbidity rates. Although thoracic surgeons usually address thoracic trauma, treatment and follow-up of many patients are performed by general surgeons in places where no thoracic surgeon is available or in cases with multi-trauma. Tube thoracostomy is a tool with unique diagnostic and therapeutic capabilities. The question of whether a general surgeon requires the aid of a thoracic surgeon in all cases has been widely addressed by the real-world practices of general surgeons. The lifesaving capacity of tube thoracostomy due to its facile application should not be overlooked by general surgeons due to concerns of malpractice.

The aim of the present study was to discuss our approach to patients with thoracic trauma in our center, where no thoracic surgeon is available.

\section{MATERIAL AND METHODS}

Written informed consent was obtained from each patient. The study protocol was approved by the local Ethics Committee. The study was conducted in accordance with the principles of the Declaration of Helsinki. A total of 89 patients with thoracic trauma who were admitted to the emergency department of our hospital, who underwent tube thoracostomy, and who were followed at the general surgery outpatient clinic between January 2008 and December 2013 were retrospectively analyzed. Patients with tube thoracostomy due to iatrogenic causes or due to other operations or interventions were excluded from the study. The patients included in the study were evaluated in terms of age, sex, etiology of the trauma, clinical signs, accompanying trauma, applied surgical interventions, referral to an advanced center, and mortality. All patients were evaluated by physical examination, laboratory tests, and radiology and were monitored with serial posteroanterior chest X-rays. Additional imaging, such as thoracic computed tomography (CT), was performed if required. Patients with extra-thoracic injury were treated and monitored concomitantly by relevant specialists. 


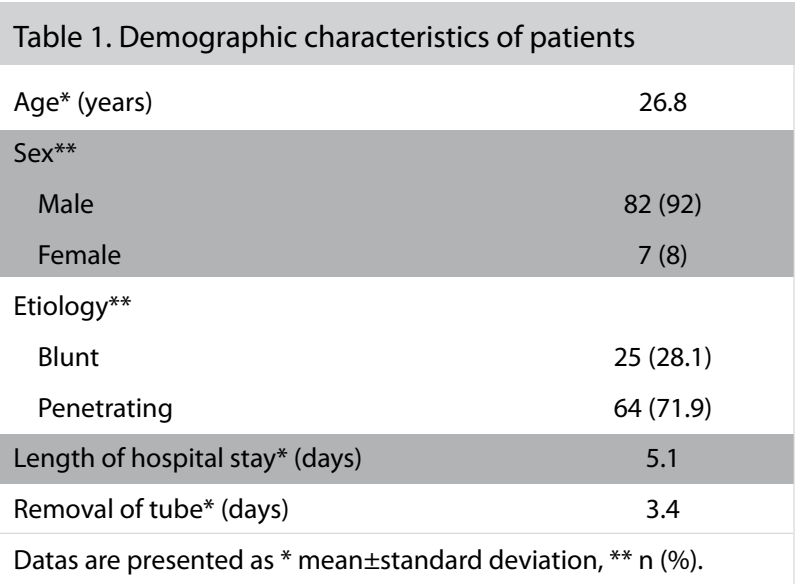

Table 2. Etiological causes

\begin{tabular}{|lcc|}
\hline Etiology & $\mathbf{n}$ & $\%$ \\
\hline Stab wounds & 61 & 69 \\
\hline Traffic accident & 11 & 12 \\
\hline Fall & 9 & 10 \\
\hline Beating & 5 & 6 \\
\hline Gunshot & 3 & 3 \\
\hline Total & 89 & 100 \\
\hline
\end{tabular}

Table 3. Clinical signs

\begin{tabular}{|lcc|}
\hline Findings & $\mathbf{n}$ & $\%$ \\
\hline Pneumothorax & 58 & 65 \\
\hline Hemopneumothorax & 22 & 25 \\
\hline Hemothorax & 9 & 10 \\
\hline Total & 89 & 100 \\
\hline
\end{tabular}

Table 4. Other thoracic pathologies

\begin{tabular}{|lll|}
\hline Other thoracic pathologies & $\mathbf{n}$ & $\%$ \\
\hline Multiple rib fracture & 8 & 8 \\
\hline Single rib fracture & 4 & 4 \\
\hline Subcutaneous emphysema & 6 & 7 \\
\hline Diaphragmatic injuries & 5 & 6 \\
\hline Pulmonary contusion & 3 & 3 \\
\hline Heart injury & 2 & 2 \\
\hline Scapula fracture & 1 & 1 \\
\hline Clavicle fracture & 1 & 1 \\
\hline
\end{tabular}

Table 5. Extra-thoracic pathologies

\begin{tabular}{|lcc|}
\hline Extra-thoracic pathologies & $\mathbf{n}$ & $\%$ \\
\hline Abdominal & 17 & 19 \\
\hline Lower extremity & 8 & 9 \\
\hline Upper extremity & 7 & 8 \\
\hline Cranial & 3 & 3 \\
\hline Peripheral vascular & 1 & 1 \\
\hline Total & 35 & 39 \\
\hline
\end{tabular}

\section{Statistical Analysis}

Data concerning demographicand clinical characteristics were analyzed by using descriptive methods (means, minimummaximum). The statistical software used was Statistical Package for the Social Sciences for Windows, version 15.0 (SPSS Inc.; Chicago, IL, USA)

\section{RESULTS}

Of all the patients, 82 (92\%) were male and seven (8\%) were female, with a mean age of 26.8 (range: 7-77) years (Table 1). Tube thoracostomy was performed in the left hemithorax, right hemithorax, and bilaterally in 53, 33, and 3 patients, respectively. Posteroanterior chest X-rays were obtained in all patients except three, whose general conditions were poor. CT was obtained in 33 patients (37\%) for whom further imaging was necessary. Penetrating trauma was found in 61 patients $(68 \%)$; this was the most common cause of thoracic trauma. Other etiological causes are shown in Table 2. Pneumothorax, the most common clinical sign, was found in 57 patients (64\%), followed by hemopneumothorax in 21 patients (23\%). Other findings are shown in Table 3, 4. Abdominal pathologies, the most common concomitant extrathoracic pathologies, were found in 17 patients (19\%), followed by extremity pathologies in 15 patients (17\%). Other extra-thoracic pathologies are shown in Table 5. Fifteen patients $(17 \%)$ underwent laparotomy due to intra-abdominal organ injury. Splenic trauma and diaphragmatic injury were detected in five patients, while two patients underwent splenorrhaphy and three underwent splenectomy. Diaphragm injuries were repaired in all these patients. Other reasons for laparotomy included injuries to the liver, small bowel, urinary bladder, stomach, and colon (Table 6). One patient who was admitted to the hospital due to a motor vehicle accident had first- and second-degree burns in an area less than $10 \%$ of the body surface. One patient had a fracture of the mandible. Three patients died during the first hour after arrival at the hospital due to additional cranial pathologies. Pneumothorax was present in three patients with cranial pathologies; however, no hemothorax was detected. Emergency thoracotomy was performed following the development of severe hypotension in two patients who had isolated thoracic penetrating knife injuries that penetrated the thoracic cavity. Left ventricular and left atrial injuries were each found in one patient. Both patients were stable postoperatively and were discharged uneventfully on the fifth and eighth postoperative days, respectively.

Complications were seen in two patients (2.2\%): one had an air leak and one had persistent pneumothorax. Nine patients (10\%) were referred to an advanced medical center after the first intervention was performed due to severe hemorrhagic drainage from the thoracic tube in six patients, persistent pneumothorax in one patient, and prolonged air leak in one patient. One patient was referred to a center with a cardiovascular surgery clinic due to popliteal artery injury. Feedback reports revealed that three patients with high levels of drainage were treated by thoracotomy, while others were treated nonsurgically; all the patients were discharged in good condition. The mean hospital stay and mean time to extubation in the early period, excluding the aforementioned nine patients and three death events, were 5.1 (range: 2-14) and 3.4 (range: 1-7) days, respectively. 
Table 6. Causes for laparotomy

\begin{tabular}{|llcc}
\hline Laparotomy & Operations & $\mathbf{n}$ & $\%$ \\
\hline Splenic and diaphragmatic injury & Splenorrhaphy $(\mathrm{n}=2)$, splenectomy $(\mathrm{n}=3)$, diaphragm repair $(\mathrm{n}=5)$ & 5 & 6 \\
\hline Liver injury & Primary repair & 4 & 5 \\
\hline Small bowel injury & Primary repair & 3 & 1 \\
\hline Bladder injury & Primary repair & 1 & 1 \\
\hline Stomach injury & Primary repair & 1 & 1 \\
\hline Colon injury & Primary repair & 1 & 1 \\
\hline Total & & 15 & 17
\end{tabular}

\section{DISCUSSION}

Mortality and morbidity are high in blunt or penetrating thoracic traumas; the mortality rate of all thoracic trauma cases is approximately $4 \%-20 \%$ (1). Thoracic trauma is the third most common type of trauma, following head and extremity trauma $(2,3)$. Blunt and penetrating traumas cause other organ injuries in $75 \%$ of cases, which substantially increases the rates of mortality and morbidity (2). In the literature, the rates of penetrating and blunt trauma have been reported to be variable. Leblebici et al. (4) reported an incidence of penetrating trauma of $63.3 \%$. However, blunt trauma was reported to be more common in several studies, while penetrating trauma accounted for $30 \%$ of cases $(5,6)$. The incidences of blunt and penetrating trauma were also reported to be $58.7 \%$ to $75.8 \%$ and $24.1 \%$ to $41.3 \%$, respectively $(4,7-10)$. In the present study, 25 patients (28.1\%) had blunt trauma and 64 patients $(71.9 \%)$ had penetrating trauma. The different rates of penetrating and blunt trauma in our study are mostly due to socioeconomic status and the proximity of the research area to a region with busy roads.

In addition, thoracic traumas have been reported to occur more frequently in men $(4,8,9)$. Consistent with this finding, 82 patients (92\%) were male in our study. Furthermore, the most frequent bone pathologies accompanying thoracic traumas are single or multiple rib fractures. In addition to rib fractures, clavicle, scapula, and sternal fractures have been reported $(8,9)$. Although sternal fractures are rare, the risk of cardiac injury is increased in those cases, particularly in the presence of rib fractures (11). Similarly, in the present study, rib fractures were the most common bone pathology. We also found cardiac injury in two patients. In both patients, the etiological cause was penetrating injury but not blunt trauma. Rupture of the diaphragm is seen principally on the left side due to a sudden increase in intra-abdominal pressure (12-14). Five patients (6\%) had diaphragmatic injury in the present study; all were repaired using an abdominal approach.

Hessani et al. (15) and Martin et al. (16) reported the duration of hospital stay in patients who underwent thoracic tube placement to be 4.1 days and 10.4 days, respectively. Removal of the tube was reported after 5.9 and 3 days by Martin et al. (16), and Younes et al. (17), respectively. In the present study, the mean hospital stay and mean duration until extubation were 5.1 days and 3.4 days, respectively. Complications of tube thoracostomy include persistent air leak, persistent pneumothorax, recurrent pneumothorax, and non-functioning tube. In several studies, the rate of complications was reported to vary between $4.8 \%$ and $30 \%$ (16-20), consistent with our study findings (2.2\%). Duration of the removal of the tube, length of hospital stay, and development of complications related to the thoracic tube have been associated with severity of injury. The specialty of the health professional, such as surgery or emergency medicine, inserting the thoracic tube and the team transporting the patients have been also implicated in the development of complications (16).

In a study reported by general surgeons, 110 patients with thoracic trauma were evaluated; 14 complications (12.7\%) were seen where procedures other than tube thoracostomy were undertaken by general surgeons alone, which resulted in higher complication rates compared to our study (21). According to Ball et al. (22), complications may vary depending on the training discipline. The rates of complications in general surgery, internal and family medicine, other surgical disciplines, and emergency medicine were $7 \%, 13 \%, 25 \%$, and $40 \%$, respectively. Bevis et al. (23) also reported that complication rates decreased from $12 \%$ to $8 \%$ when surgeons with advanced practice skills treated the patients rather than trauma surgeons. In another study supporting the previous study, Etoch et al. (19) showed that the rate of complication was $6 \%$ in patients treated by thoracic surgeons, while it was $13 \%$ in patients treated by emergency physicians. Moreover, they stated that referring all patients to a thoracic surgeon resulted in a complication rate of $38 \%$. The results of our study were different from what we expected compared to previous studies. We consider that the reduced duration of hospitalization, time to extubation, and complication rates may all be due to the fact that patients with severe injuries were referred to more advanced centers.

In addition, extremity fractures have been reported to be the most common extra-thoracic pathologies (50\%-54\%). Head trauma $(27.4 \%-44 \%)$ and abdominal injuries (13.7\% to $21 \%)$ are among the other commonly seen extra-thoracic pathologies $(24,25)$. However, these rates were found to be lower in the present study. The most common extra-thoracic pathology was abdominal injury (19\%). Extremity fractures were seen in $17 \%$ of the patients, while head trauma was seen in $3 \%$ of the patients. The most common injury was splenic damage among the patients requiring laparotomy. Appropriate interventions were performed in patients with intra-abdominal injuries.

In contrast, no mortality was seen in any patients with thoracic trauma who underwent tube thoracostomy in the present study. We consider that the most important reasons for 
this result are the timely diagnosis of patients with severe injury, timely initial intervention, and appropriate referrals to advanced centers. Therefore, the motto of a general surgeon should be not to refer every patient to tertiary centers and not to delay referral in selected cases to achieve acceptable rates of mortality and morbidity.

\section{CONCLUSION}

All general surgeons should be highly familiar with approaches to thoracic trauma, and necessary interventions should be performed in emergency situations. It is also essential to correctly identify patients who require timely and appropriate referral to a tertiary center to reduce the rates of mortality and morbidity.

Ethics Committee Approval: Ethics committee approval was received for this study from the ethics committee of Haseki Training and Research Hospital.

Informed Consent: Written informed consent was obtained from patient who participated in this study.

Peer-review: Externally peer-reviewed.

Author Contributions: Concept - C.T.; Design - C.T.; Supervision - C.T., T.K., A.K.; Resource - C.T.; Materials - C.T., B.O., M.C.K., A.A., K.B.; Data Collection and/or Processing - C.T., B.O., M.C.K., A.A., K.B.; Analysis and/ or Interpretation - C.T., A.K., T.K.; Literature Search - C.T., B.O., M.C.K., A.A., K.B.; Writing Manuscript - C.T.; Critical Reviews - A.K., T.K.

Conflict of Interest: No conflict of interest was declared by the authors.

Financial Disclosure: The authors declared that this study has received no financial support.

\section{REFERENCES}

1. Battle $C E$, Hutchings $H$, Evans PA. Risk factors that predict mortality in patients with blunt chest wall trauma: a systematic review and metaanalysis. Injury 2012; 43: 8-17. [CrossRef]

2. Basoglu A, Akdag AO, Celik B, Demircan S. Thoracic trauma: an analysis of 521 patients. Ulus Travma Acil Cerrahi Derg 2004; 10: 42-46.

3. Regel G, Lobenhoffer P, Grotz M, Pape HC, Lehmann U, Tscherne $\mathrm{H}$. Treatment results of patients with multiple trauma: an analysis of 3406 cases treated between 1972 and 1991 at a German Level I Trauma Center. J Trauma 1995; 38: 70-78. [CrossRef]

4. Leblebici IH, Kaya Y, Kocak AH. Analysis of 302 cases with chest trauma. Türk Gögüs Kalp Damar Cer Derg 2005; 13: 392-396.

5. Karamustafaoglu YA, Yavasman I, Kuzucuoglu M, Mammedov R, Yener Y. Our clinical experience with penetrating thoracic trauma patients in the last 13 years. Trakya Univ Tip Fak Derg 2009; 26: 232-236.

6. Harrington DT, Phillips B, Machan J, Zacharias N, Velmahos GC, Rosenblatt MS, et al. Research Consortium of New England Centers for Trauma (ReCONECT): Factors associated with survival following blunt chest trauma in older patients: results from a large regional trauma cooperative. Arch Surg 2010; 145: 432-437. [CrossRef]

7. Er M, Işık AF, Kurnaz M, Çobanoglu U, Sagay S, Yalçınkaya I. Clinical results of four hundred and twenty-four cases with chest trauma. Ulus Travma Acil Cerrahi Derg 2003; 9: 267-274.

8. Tekinbas C, Eroglu A, Kurkcuoglu IC, Turkyilmaz A, Yekeler E, Karaoglanoglu N. Chest trauma: Analysis of 592 cases. Ulus Travma Acil Cerrahi Derg 2003; 9: 275-280.

9. İmamoğlu OU, Öncel M, Erginel T, Tunçay E, Dalkılıç G, et al. Approach to thorax trauma: summary of 110 cases. Türk Göğüs Kalp Damar Cer Derg 1999; 7: 450-453.

10. Çakan $A$, Yüncü $G$, Olgaç $G$, Timuçin $A$, Sevinç $S$, Kaya ŞÖ, et al. Thoracic trauma: Analysis of 987 patients. Ulus Travma Acil Cerrahi Derg 2001; 7: 236-241.

11. Eren MN, Balcı AE. Toraks travmaları. In: Ökten I, Güngör A, editörler. Göğüs Cerrahisi. Ankara: Sim Matbaacılık; 2003; s.661-688.

12. Yalçınkaya I, Kaya $S$, Taştepe AŞ. Surgical approach to thorax traumas. Ulus Travma Acil Cerrahi Derg 1995; 1: 27-31.

13. Symbas PN, Vlasis SE, Hatcher C. Blunt and penetrating diaphragmatic injuries with or without herniation of organs in to the chest. Ann Thorac Surg 1986; 42; 158-162. [CrossRef]

14. Hood Rm: Injuries involving the diaphragm. In Hood RM, Boyd AD, Culliford AT (editors). Thoracic Trauma WB Saunders Company. 1989, pp267-89.

15. Hessami MA, Najafi F, Hatami S. Volume threshold for chest tube removal: a randomized controlled trial. J Inj Violence Res 2009; 1: 33-36. [CrossRef]

16. Martin M, Schall CT, Anderson C, Kopari N, Davis AT, Stevens P, et al. Results of a clinical practice algorithm for the management of thoracostomy tubes placed for traumatic mechanism. Springer Plus 2013; 2: 642-647. [CrossRef]

17. Younes RN, Gross JL, Aguiar S, Haddad FJ, Deheinzelin D. When to remove a chest tube? A randomized study with subsequent prospective consecutive validation. J Am Coll Surg 2002: 195: 658-662. [CrossRef]

18. Menger R, Telford G, Kim P, Bergey MR, Foreman J, Sarani B, et al. Complications following thoracic trauma managed with tube thoracostomy. Injury 2012; 43: 46-50 [CrossRef]

19. Etoch SW, Bar-Natan MF, Miller FB, Richardson JD. Tube thoracostomy. Factors related to complications. Arch Surg 1995; 130: 521525. [CrossRef]

20. Bailey RC. Complications of tube thoracostomy in trauma. J Accid Emerg Med 2000; 17: 111-114. [CrossRef]

21. Demirhan R, Kucuk HF, Kargi AB, Altıntas M, Kurt N, Gulmen M. Evaluation of 572 cases with blunt and penetrating trauma. Ulus Travma Acil Cerrahi Derg 2001; 7: 231-235.

22. Ball CG, Lord J, Laupland KB, Gmora S, Mulloy RH, Alex KN, et al. Chest tube complications: How well are we training our residents? J can chir 2007; 50: 450-459.

23. Bevis LC, Berg-Copas GM, Thomas BW, Vasquez DG, Wetta-Hall R, Brake $D$ et al. Outcomes of tube thoracostomies performed by advanced practice providers vs trauma surgeons. Am J Crit Care 2008; 17: 357-363.

24. AlEassa EM, Al-Marashda M, Elsherif A, Eid HO, Abu-Zidan FM. Factors affecting mortality of hospitalized chest trauma patients in United Arab Emirates. J Cardiothorac Surg 2013; 8: 57-58. [CrossRef]

25. Shorr RM, Crittenden M, Indeck M, Hartunian SL, Rodriguez A. Blunt thoracic trauma. Analysis of 515 patients. Ann Surg 1987; 206: 200-205.[CrossRef] 